\title{
Erratum to: Twenty-first Meeting of the European Neurological Society 28-31 May, 2011 Lisbon, Portugal
}

\section{Symposia and Free Communications}

The Publisher

Published online: 13 July 2011

(C) Springer-Verlag 2011

Erratum to: J Neurol (2011) 258(Suppl 1):S1-S295

DOI 10.1007/s00415-011-6026-9

At the ENS 2011 abstract supplement, two reviewers were missing on page 1: P. Annunziata, S. Papageorgiou.

We would like to thank for precious help and assistance.

One author was missing in abstract P909. The correct author line is given here.

Positive effect of modafinil on EDSS progression in multiple sclerosis

R. H. Bibani, C. Tench, C. Constantinescu

The University of Nottingham (Nottingham, UK)

The online version of the original article can be found under doi:10.1007/s00415-011-6026-9.

The Publisher

Springer Verlag, Heidelberg, Germany 